Vilser, Walthard; Nagel, Edgar; Lanzl, Ines Maria Antonie:

Retinalvessel analysis - new possibilities

Zuerst erschienen in: Biomedizinische Technik = Biomedical Engineering. - Berlin [u.a.] : de Gruyter. - 47 (2002), S1b, S. 682-685.

Jahrestagung der Deutschen Gesellschaft für Biomedizinische Technik (DGBM) im VDE ; 36 (Karlsruhe) : 2002.09.25-27

Erstveröffentlichung: 2002

Datum Digitalisierung: $2009-11-26$

ISSN (online): $\quad$ 1862-278X

ISSN(print) 0013-5585

DOI: $\quad$ 10.1515/bmte.2002.47.s1b.682

[Zuletzt gesehen: 2019-12-12]

„Im Rahmen der hochschulweiten Open-Access-Strategie für die Zweitveröffentlichung identifiziert durch die Universitätsbibliothek IImenau."

"Within the academic Open Access Strategy identified for deposition by IImenau University Library."

„Dieser Beitrag ist mit Zustimmung des Rechteinhabers aufgrund einer (DFGgeförderten) Allianz- bzw. Nationallizenz frei zugänglich."

„This publication is with permission of the rights owner freely accessible due to an Alliance licence and a national licence (funded by the DFG, German

Research Foundation) respectively."

\section{DFG}

Nationallizenzen 


\title{
RETINAL VESSEL ANALYSIS - NEW POSSIBILITIES
}

\author{
W. Vilser ${ }^{1,4}$, E. Nagel ${ }^{2}$, I. Lanzl ${ }^{3}$ \\ ${ }^{1}$ Technical University of Ilmenau, Institut BMTI, Germany \\ ${ }^{2}$ Ophthalmic private practice, Rudolstadt, Germany \\ ${ }^{3}$ Department of Ophthalmology, Technical University of Munich, Germany \\ ${ }^{4}$ Imedos $\mathrm{GmbH}$, Weimar, Germany \\ w.vilser@imedos.de
}

\begin{abstract}
Retinal Vessel Analysis is a new technique to assess behavior of large retinal vessels based on diameter measurements. The Retinal Vessel Analyzer (RVA) measures continuously on-line obtaining data in relation to time and local position. Possible analysis tools include (a) Time Course Analysis of physiological, pathological, or therapy induced changes; (b) Local Course Analysis to recognize local narrow or wide vessel segments along the vessel; (c) Vasomotoric Analysis to deternine vasomotions and blood pressure related diameter changes; $(d)$ Functional Analysis to examine dynamic behavior e.g. the ability to autoregulate and (e) Functional Imaging to visualize functional parameters of vessels in single vessel segments. RVA is thus able to recognize and study different autoregulation mechanisms. (Supp. BMBF-13N8001)
\end{abstract}

Keywords- RVA, vessel analysis, functional imaging, diameter

\section{Introduction}

The vessel diameters are the essential adjusting elements of autoregulation. They are influenced by age, pathologic and therapeutic changes. Large retinal vessels with diameters between 200 to $100 \mu \mathrm{m}$ and less influence retinal microcirculation and control blood flow, capillary pressure distributions and substance exchange. Most known methods for diameter measurement estimate only one diameter value off line at one local measuring point and at one time point. Thus they cannot supply the necessary information about functional temporal and local vessel behavior.

Aim of Retinal Vessel Analysis is to develop methods to examine function and individual capacities of vessel segments along the vessels. It is based on on-line diameter measurements. Analysis is able to recognize diameter changes in response to functional demands and changes due to compensation of disturbances in microcirculation. It may define vascular risk factors, early but still reversible pathologic changes and therapeutic effects.

\section{Materials and Methods}

To demonstrate the potential possibilities of the Retinal Vessel Analysis examples from experimental studies in healthy volunteers and groups of patients are described in the results section. All studics were performed hy Retinal Vessel Analyzer (RVA, Imedos GmbH Weimar, Germany).
The RVA was developed to analyze large retinal arteries and veins as previously described $[1,2]$. The instrument measures vessel diameter in relation to time and local position along a vessel in real time or from tape recordings off line. It measures continuously (time resolution: $\geq 25 / 5$; measuring resolution: $<1 \mu \mathrm{m}$; local resolution: $180 \mu \mathrm{m} /$ vessel segment; measuring time: $1 \mathrm{~s}$ to $10 \mathrm{~min}$ ) from a video picture sequence of the retina. Resulting is a measurement data basis. Data of a whole session or parts of it can be selected and exported to be analyzed by RVA programs or external programs. Methods for vessel analysis consist of the following groups:

Time course analysis

Local course analysis

Vasomotoric analysis

Functional analysis

Functional imaging

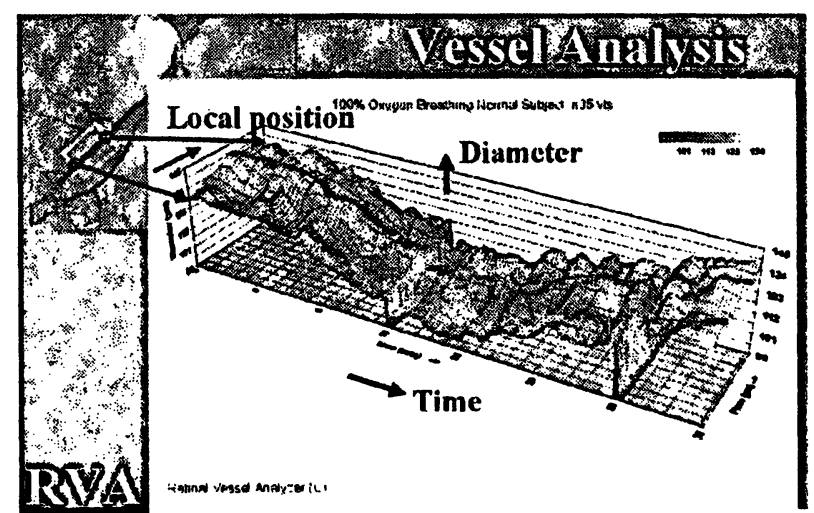

Fig. 1: Measuring data basis of RVA (venous reaction to $100 \%$ oxygen breathing; zero values indicate temporary' measurement interruption)

3 dimensional display of RVA data hasis for a venous segment is shown in fig 1 . The retinal image documents the location of the measurement vindow (yellow) and which part of the vessel is examined. The vessel within the window is divided into vessel segments of about $18(\mu \mathrm{mm}$ length. For each image of the video sequence the dianneter of one vessel segment is measured and is assigned 10 a time point and to the local pessition of the measurement point along the vessel. Thus a local course of dianiter along the vessel will be assessed within a short tine penial (7-axis in the diagram). Continuous measurenkents result in a time course observing dynamic (tempurall) veswel byhs ior along the time axis ( $x$-axis in the diagram ).

Vessels are not stiff tules. The 3. Dediagram in lig. I

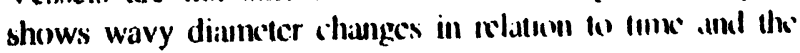


local course along the vessel. These local changes can amount (o) 10\% of the mean diameter and inore. Therefore a representative vessel diameter should be delined as statistical predictand over a given time period and vessel length.

\section{Results}

Time Course Analysis compares vessel diameters obtained all different sessions to examine age related, pathologic, or therapy induced changes. The advantages of RVA consist in the high accuracy of mein values calculated for the examination time period and examined vessel length as well as the high degree of local independence in single case examinations. The whole 3-D diagram of fig. 1 can be reduced to one mean value.

Local Course Analysis is able to recognize local narrow or wide vessel segments along the vessels. To obtain the local course along the vessel RVA calculates the means of measurement values over the measurement time. The 3-D diagram of the data basis is reduced to a 2-D diagram representing the diameter in relation to local position along the vessel (local course). The advantage consists in the ability to compare diameter changes segment for segment, for narrow and wide vessel segments along the vessel. Therefore RVA allows evaluation of the local course of diameter changes along the vessel segment. Control of blood flow is influenced especially by the narrow vessel segments. Studies show (see also fig 8 and 9 ) that diameter change is different in different vessel segments according to functional need and underlying pathology.

Vasomotoric Analysis examines the temporal wavy changes which can be seen in the data basis of fig. 1 . These diameter changes of retinal vessels can be caused by blood pressure waves e.g. pulsations or by vasomotions (myogenic wavy activities).

The analysis of segmental changes in diameter pulsation magnitudes or pulsation form includes information about stiffiness and / or contractile state of each vessel segment. Analysis of vasomotions could also be used to recognize effects of polyneuropathies. Limits to date are the detection of small diameter changes caused by pulsations, because their changes amount to $1 \%$ of mean diameter or less.

The aim of Functional Analysis is to provide an artificial functional stimulus and to analyze the temporal diameter response of vessels to compensate for the provoked changes in microcirculation.

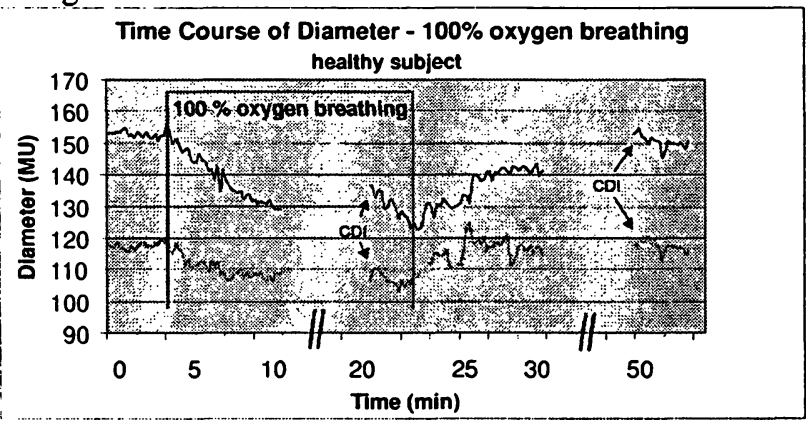

Fig. 2: Time course of response to $100 \%$ oxygen breathing (superior temporal vein, superior temporal artery)
Provocation stimuli for retinal microcirculation include changes in breathing gas composition, functional light stimuli. changes in systemic blood pressure or intraocular pressure (IOP) and others.

Fig. 2 represents arterial and venous diameter responses to 20 minutes of $100 \%$ oxygen breathing. Fig. 1 displays the whole data basis of the venous vessel for comparison. The temporal vessel response in fig. 2 is the representation of the mean of measurement values over all vessel segments. For the venous reaction the 3-D-diagram of fig. 1 is reduced to a 2- D- diagram in fig. 2. Vessels undergo constriction during provocation. Arterial response is less then venous response. After provocation vessel diameters return to baseline values. A possible provocation to examine myogenic reactions consists in increasing systemic blood pressure by isometric exercise.

Time course response is represented in fig. 3 as means over time periods in healthy volunteers.

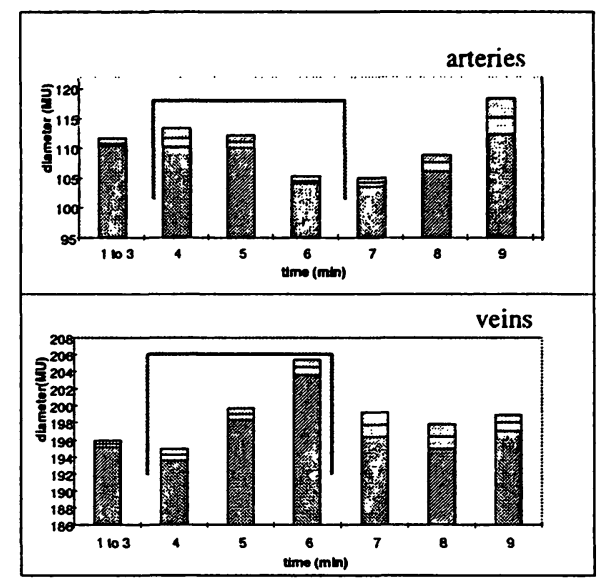

Fig. 3: Group mean of time course response to isometric exercise (green box) known as Bayliss effect

Momentary increase in blood pressure causes dilation of arterial vessel diameter. During further increase of blood pressure the arterial diameter is decreasing. This effect is known as Bayliss effect. Venous diameters react in an opposite way to the provocation.

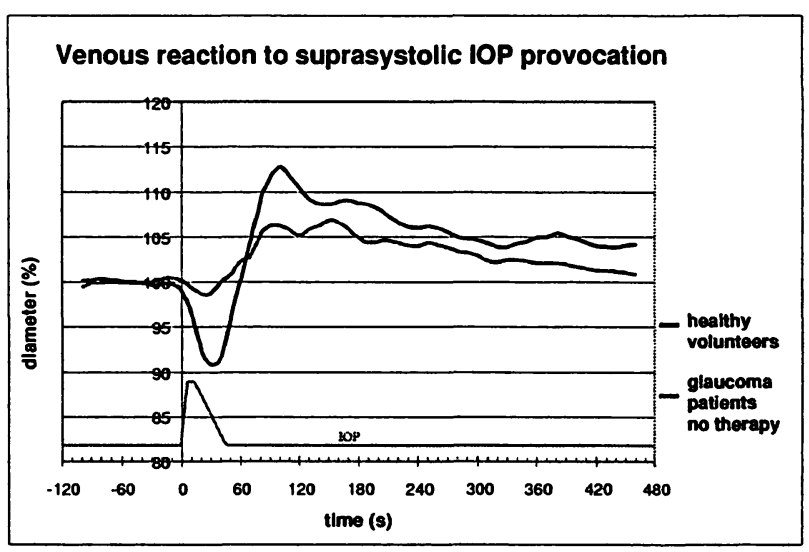

Fig. 4: Time course response to suprasystolic IOP increase (glaucoma patients and age matched volunteers)

Time course in fig. 4 represents group mean responses to IOP rise to suprasystolic values (see schematic IOP course 
red line) in veins of healthy age matched (blue line) and glaucoma patients (green line).

Vessels are compressed during provocation and react by considerable dilation after provocation. The ability to dilate is reduced significantly in the glaucoma group.

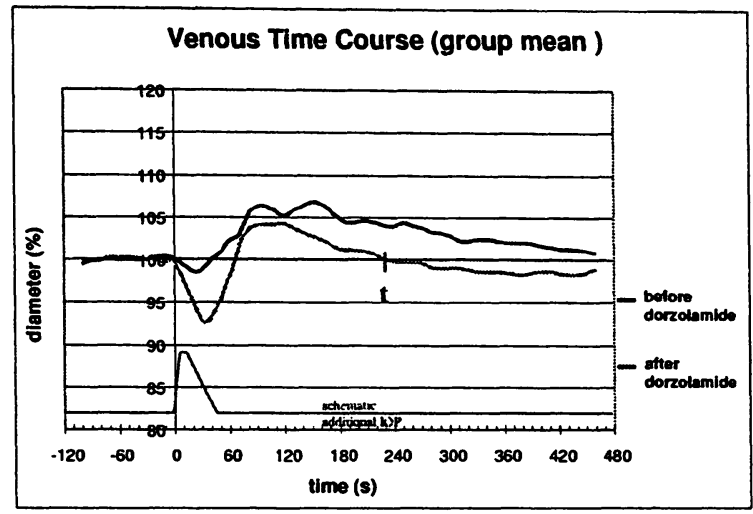

Fig. 5: Temporal response before and after treatment

The time course responses to the same provocation and for the same glaucoma group can be compared before (green) and after (dark-green) treatment with dorzolamide eye drops (fig.5). Comparison shows no improved ability to dilate but a considerably shorter dilation period (intersection $t$ between time course and baseline - blue). If we assume, that the venous dilation indicates the postischaemic autoregulative compensation period then treatment might improve autoregulation during and/or after provocation by accelerating autoregulatory compensation (5 $\mathrm{min}$ compared to more than $10 \mathrm{~min}$ before treatment). That could imply that postischaemic periods may be considerably shorter with treatment. In addition venous diameter drops even under baseline values and indicates a counterregulation.

Previous studies without provocation could not prove any retinal diameter changes before and after treatment with dorzolamide. Changes could be elucidated only in the dynamic vessel response to a provocation stimulus.

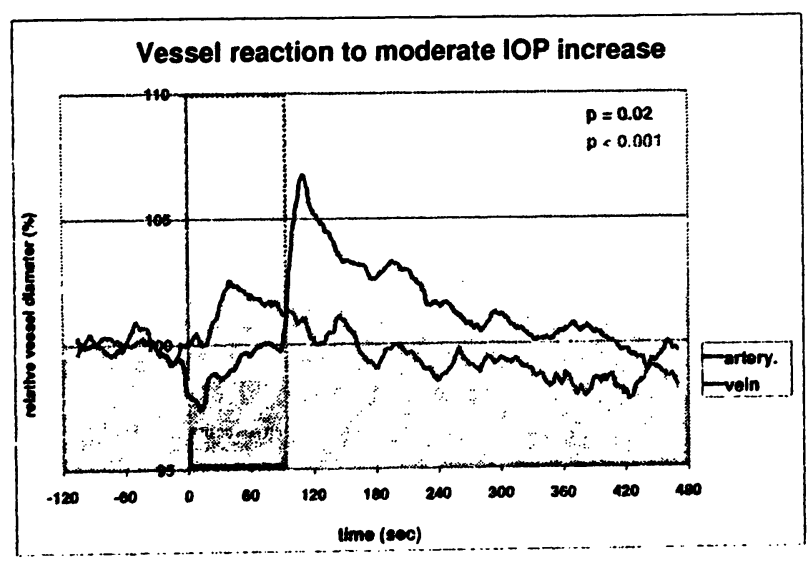

Fig. 6: Temporal response to small IOP increase.

Study of time course responses to small IOP increases (rapid rise by $20 \mathrm{mmHg}$ after baseline measurement and release after 1,5 minutes - see marked period in the dia- gram) is represented in fig. 6. Arterial and venous responses are different and opposite. During provocation arteries respond by increasing diameter, veins by decreasing. After provocation venous diameter increases while arterial diameter decreases. Veins show a considerable dilation with slow return while arteries show strong counterregulation after cessation of provocation.

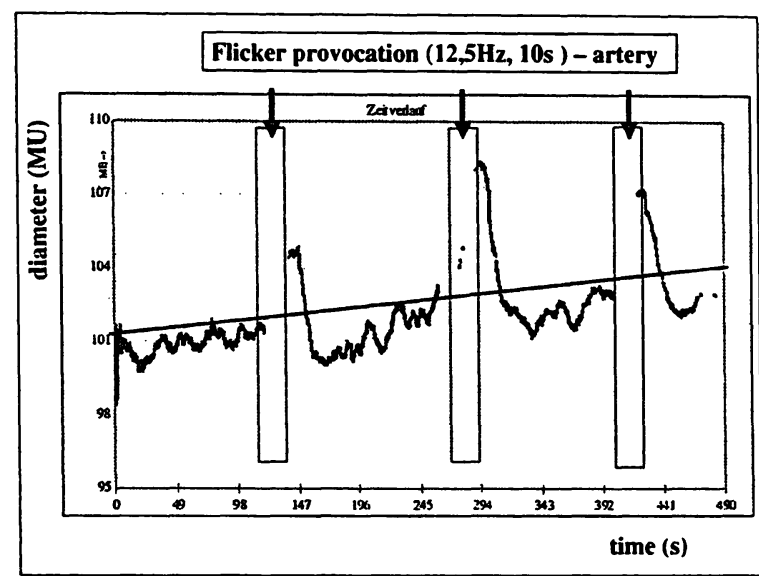

Fig 7: Temporal response of diameter to flicker light

Fig. 7: represents arterial vessel response to $12,5 \mathrm{~Hz}$ flicker light. Provocation by flickering light causes vascular dilation by neurovascular coupling [Riva et al] and acts as a functional stimulus. Vessel response is very rapid without visible delay. After provocation diameter drops off to levels below baseline to counterregulate before returning to pre stimulus levels.

The aim of Functional Imaging is first the reduction of the large amount of measured values in the data basis (fig.1) to characterizing parameters which describe functions of vessels and secondly the representation of the determined functional parameters assigned to each vessel segment within the vessel image. Such functional parameters could represent the segmental autoregulation reserve, the segmental ability to constrict or the segmental vessel resistance and others.

Venous local course in response to $100 \%$ oxygen breathing

\section{$\uparrow$ diameter (MU)}

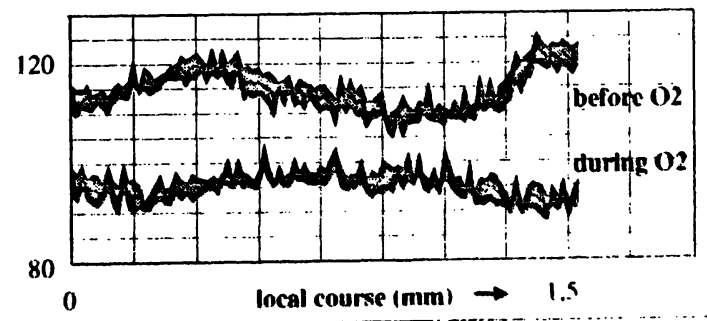

Fig. 8: Constriction reserve to anygen healthing: (healthy person, hlue $=$ confidence interval, $p=(0.05)$

Fig. 8 shows the locial course of diancter reaction lnelow and during $100 \%$ oxygen breathing detcrnincel hy calculd tion of means over chesen time perionts hetore and dermen!

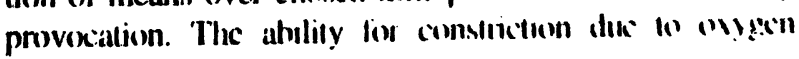


provocalion can le deternined for cach vessel segment by calculating the diflerence lxetween hoth courses. This diflerence could represient a linctional paumeter for the ahility to consstrict.

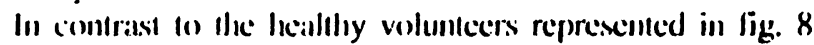
in a paltient with systcmic hypertension (lig. 9) vessel segments lost constriction albility during oxygen provecaation.

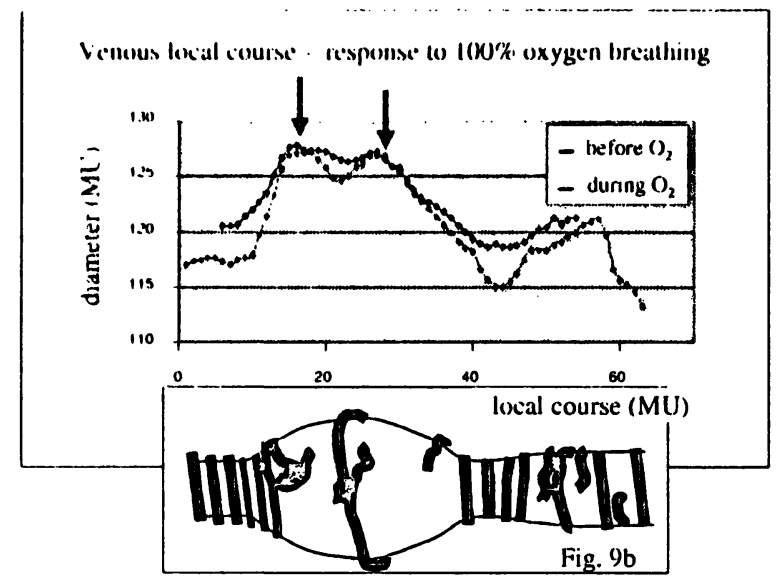

Fig 9: Constriction reserve of hypertensive patient (9b: Vessel with loss of smooth muscles modified [6])

\section{Discussion}

Historically the Bayliss effect is considered as autoregulation. If we define that retinal autoregulation represents the ability to compensate for disturbances in microcirculation or altered functional demands of surrounding tissue we have to extend the historical meaning of autoregulation. Therefore autoregulation is a generic term for different local feedback control systems, superimposed on each other influencing the vessel diameter as the adjusting element. We can therefore assess regulatory changes by measuring vessel diameter. The feedback may be caused by metabolic (metabolic autoregulation) or mechanomyogenic (Bayliss effect) conditions, or can be due to ncurovascular coupling (light changes) and others. The described examples demonstrate variant temporal (dynamic) vessel responses. Vessel behavior ranges from dynamic changes within seconds (flicker responses) to minutes (metabolic responses). By application of special provocation methods it is possible to select and examine different autoregulative systems. Using the RVA we can recognize different autoregulative systems by assessment of temporal dynamic behavior of vessel responses. Estimation of autoregulation range (dilation reserve and constriction reserve) in different autoregulative systems has a very high potential to indicate vascular risk factors, early involvement of functional changes and disturbances of microcirculation as shown by the IOP provocation stimulus.

Other studies demonstrate [4] that autoregulation ability to constrict against blood pressure rise is reduced in advanced age and diabetic angiopathy. Similar results are obtained by means of RVA [3] when breathing $100 \%$ oxygen. The vessel response to $100 \%$ oxygen breathing should not be an autoregulative response. However the segmental constriction describes the ability to constrict which is an im- portant scgmental vessel function for autoregulation. Reduced constriction of wide vessel segments may be interpreted as reduced ability for muscular constriction or segmental loss of smooth muscles within the affected vessel scemunts (fig. 9b). This effect was described in hypertensive and diabetic patients [6].

Our results presented here demonstrate the problems inherent to conventional measurement methods, which estimate only one value at onc locial and temporal measurement point (see fig. 1). These methods are only usable for static time course analysis and only for study results of group means. Onc cssential advantage of RVA is the ability to detect temporal and local vessel changes characterizing single vessel segments and individual eyes with high accuracy, a feature not obtainable with other methods. The RVA can select, recognize and evaluate different autoregulation mechanisms and their individual reserve for single vessel segments in single eyes of an individual patient. Therefore physiologic and pharmacologic research, screening of vascular risk factors, early recognition of retinal diseases and individual optimization and quality management of therapeutic approaches is feasible.

\section{Acknowledgement}

OIT-OpththalmoInnovation Thüringen, Supp. by BMBF13N8001)

\section{Bibliography}

[1] W. Vilser, Th. Riemer, Ch. Bräuer-Burchardt, K. Münch, I. Senff, W. Kleen, K. Bachmann, S. Pietscher, G. E. Lang, G. K. Lang, "Retinal Vessel Analyzer (RVA) a new measuring system for examination of local and temporal vessel behavior", [ARVO-Abstract] Invest Ophthalmol Vis Sci, vol.38(4), S1050 Abstract nr 4897, 1997

[2] U. Seifert, W. Vilser, „Retinal Vessel Analyzer (RVA) -Design and Function", Biomed Tech, Ergänzungsbd., Vol 47. 36. Jtg. DGBMT, 2002, No.2043, 2002

[3] G. Fuhrmann, E. Nagel, W. Vilser, G. E. Lang, "Does diabetes mellitus cause the reduction of retinal vessel reactivity to $100 \%$ oxygen breathing? - a RVA study", [ARVO-Abstract] Invest Ophthalmol Vis Sci., vol. 40(1), S679, Abstract nr 3581, 1999

[4] M.Blum, U.Kubetschka, W. Hunger-Dathe, K. Bachmann, U.A. Müller, J. Strobel, „Autoregulation retinaler Arteriolen bei Patienten mit Diabetes mellitus und Normalprobanden". Klin Monatsbl Augenheilkd, vol.216, pp 40-44, 2000

[5] Th. Riemer, K. Bachmann, W. Vilser, M. Blum, J. Strobel, G. K. Lang, "The Bayliss effect on retinal vessel", [ARVO Abstract], Invest Ophthalmol Vis Sci, vol.38(4), S780, Abstract nr. 3616, 1997

[6] E. Rungger-Brändle, A.A. Dosso, C. Alliod, P.M. Leuenberger. „Smooth muscle lesions in large caliber arteries and veins of the human diabetic retina". [ARVO Abstract], Invest Ophthalmol Vis Sci, vol.38(4), S770, Abstract nr. 3563, 1997 